\title{
Factors influencing cervical cancer screening in a Kenyan Health Facility: a mixed qualitative and quantitative study
}

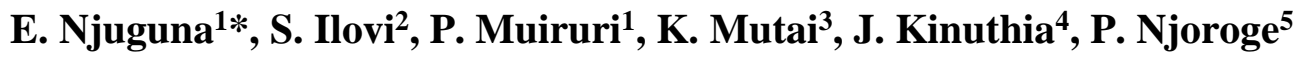 \\ ${ }^{1}$ Comprehensive Care Center, Kenyatta National Hospital, Nairobi, Kenya \\ ${ }^{2}$ Department of Medicine and Therapeutics, University of Nairobi, Nairobi, Kenya \\ ${ }^{3}$ Partners in Advanced Care and Treatment PACT, University of Nairobi, Nairobi, Kenya \\ ${ }^{4}$ Department of Obstetrics and Gynaecology, University of Nairobi, Nairobi, Kenya \\ ${ }^{5}$ School of Public Health, University of Nairobi, Nairobi, Kenya
}

Received: 01 February 2017

Accepted: 03 March 2017

\author{
*Correspondence: \\ Dr. Esther N. Njuguna, \\ E-mail: njugunadr@gmail.com
}

Copyright: ( ) the author(s), publisher and licensee Medip Academy. This is an open-access article distributed under the terms of the Creative Commons Attribution Non-Commercial License, which permits unrestricted non-commercial use, distribution, and reproduction in any medium, provided the original work is properly cited.

\begin{abstract}
Background: Cervical cancer is the commonest cause of cancer-related morbidity and mortality among women in developing countries in sub-Saharan Africa. Screening for cervical cancer among HIV infected women is crucial as they are more at risk of developing the disease and progressing faster once infected with Human Papilloma Virus (HPV).

Methods: We aimed to determine the factors affecting the utilization of cervical cancer screening among HIV infected women above 18 years of age at Kenyatta National Hospital by conducting a cross-sectional mixed quantitative and qualitative methods study. Descriptive and inferential analysis was carried out on quantitative data to determine significant associations with cervical cancer utilization. Qualitative data were analyzed after coding for significant clauses and transcribing to determine themes arising.

Results: Three hundred and twenty-eight of the total 387 women enrolled reported they had been advised by their health providers to go for screening. However, only $179(46 \%)$ reported cervical cancer screening. Women were more likely to report cervical cancer screening if recommendation by a staff was made $(\mathrm{p}<0.001)$, and prior to joining $\mathrm{KNH}$ CCC ( $\mathrm{p}<0.001)$. Qualitatively the main barrier to screening included fear of screening due to concerns about excessive pain or bleeding, lack of proper communication on screening procedures and long waiting time

Conclusions: The utilization of cervical cancer screening services was low despite high rates of health care recommendation. The women were more likely to utilize the service if recommendation from the health care worker was made, and if they had ever screened before.
\end{abstract}

Keywords: Cervical cancer, HIV, Women

\section{INTRODUCTION}

Cervical cancer is the commonest cause of cancer-related morbidity and mortality among women in developing countries in Sub Saharan Africa. Eighty-three percent of all cases of cervical cancer worldwide occur in developing countries. ${ }^{1}$ Screening for cervical cancer in all women regardless of HIV status is crucial for the early detection of cancer of the cervix when treatment is most effective in curing the disease. Among HIV infected women, incidence of cervical intraepithelial neoplasia (CIN) is 4-5 times higher than among women who are not HIV infected. ${ }^{2-4}$ Both HIV and Human Papilloma Virus (HPV) which is responsible for CIN, are sexually transmitted, with HPV persisting longer in HIV infected women thus increasing their risk of cervical dysplasia. ${ }^{5-7}$ The national guidelines recommend regular cervical cancer screening among HIV infected women by Visual 
Inspection with Acetic acid (VIA), Visual inspection with Lugol's iodine (VILI) or cervical cytology using Pap smear. ${ }^{8}$ Other measures for the prevention of cervical dysplasia include vaccination against HPV, though this method is very expensive and not readily available. Despite clear recommendations for cervical cancer screening, less than $5 \%$ of women in the general population in developing countries have been screened compared to about $75 \%$ of women in developed countries. $^{9}$ However some studies have demonstrated cervical screening rate among HIV infected women of $80 \%$ within a programmatic environment. ${ }^{10}$

This study aimed to assess utilization of cervical cancer screening and family planning services in the Kenyatta National Hospital Comprehensive Care Centre.

\section{METHODS}

This was a cross-sectional study targeting women on follow up at the Comprehensive Care Centre, Kenyatta National Hospital in Nairobi, Kenya. The clinic caters to close to 9,000 HIV infected people, $60 \%$ of whom are women. It provides free anti-retroviral therapy as well as treatment for opportunistic Infections. The outcome variable was the utilization of cervical cancer screenings in the last 2 years. The study targeted HIV-infected women above 18 years of age who had been followed up at the HIV clinic for not less than 2 years.

\section{Qualitative arm}

Purposive sampling of the study population was conducted for the qualitative arm of the study. Eligible participants were approached by a trained counselor in the clinic and requested if they are interested in participating in the study. Those who accepted were then enrolled for focus group discussions (FGDs) using key indicators including age and parity. Different groups based on age were determined to avoid mixing older women with younger women as this may have influenced their honest response to the sensitive questions.

\section{Quantitative arm}

Systematic random sampling for the quantitative arm of the study was done and interviewer administered structured questionnaires administered. Every $5^{\text {th }}$ female patient was screened to ensure they met the eligibility criteria of (1) age above 18 years, (2) enrollment into the clinic of not less than 2 years and (3) ability to consent. Those eligible were consented in their preferred language, either English or Kiswahili, before a structured questionnaire was administered by a trained research assistant.

\section{Qualitative data collection}

Four FGDs each with 6-8 participants based on the principles of qualitative research each lasting 60-90 minutes were conducted. ${ }^{11}$ Group conduct included maintaining confidentiality by ensuring that each participant was identified by number and not by name. Social demographic characteristics and key information on participant's age, parity and current use of family planning were taken prior to the FGD. The discussion was conducted and recorded using a digital recorder in the preferred language either English or Kiswahili which was translated later into English. A note taker was present during all the session and notes taken for comparison with the digital recordings.

Coding for key clauses was done using a code book before transcription. This was done by two people- the Principal Investigator and a trained research assistant. To validate the quality of translation and transcription, 50\% of the transcripts were compared with the translation.

The participants involved in the qualitative data collection were not required to participate in the quantitative data collection.

\section{Quantitative data collection}

We used structured interviewer administered questionnaires to determine the socio-demographic characteristics of the participants and factors influencing the utilization of cervical cancer screening. Descriptive and inferential analysis was done using chi square tests to determine the association between cervical cancer screening and other socio-demographic characteristics with a two sided p-value and alpha value of $5 \%$. For statistically significant associations, logistic regression odds ratio was calculated to control for confounders and determine the strength of association.

Ethical clearance was sought from the Ethical Research Committee in $\mathrm{KNH}$, Nairobi. Absolute confidentiality was accorded to the participants. Only enrolment numbers of the participants were used to avoid identification. The information was handled with utmost care and confidentiality. Illiterate participants were required to insert a thumb print in the presence of an independent witness.

\section{RESULTS}

A total of 387 participants were enrolled between January 2013 to April 2013. The median age was 40 (Inter Quartile Range of 36-44 years) (Table 1). Only 179 $(46.3 \%)$ respondents had had a cervical cancer screening test done in the clinic $328(85.2 \%)$ women reported that cervical screening had been recommended to them. Of these, $81(25 \%)$ had cervical cancer screening test before they joined the CCC clinic. Of these, 72 (88.9\%), were reported as normal, $7(8.6 \%)$ as abnormal and $2(2.5 \%)$ did not know the results.

Women were more likely to screen if advised health provider (OR 10, 95\% CI 4.2-23.9, $\mathrm{p}<0.001$ ), 
The participants who utilized the service were more likely to rate the services as being either good OR 5.4, 95\% CI 2.0-14.6, $\mathrm{p}=0.001)$ or very good (OR 8.9, 95\% CI $2.8-28.4, \mathrm{p}<0.001)$

Table 1: Selected socio-demographic characteristics of enrolled HIV infected women.

\begin{tabular}{|c|c|c|}
\hline Characteristics & $\mathbf{N}$ & $\%$ \\
\hline \multicolumn{3}{|l|}{ Occupation } \\
\hline Employed & 116 & 30.0 \\
\hline Self employed & 196 & 50.6 \\
\hline Not employed & 75 & 19.4 \\
\hline \multicolumn{3}{|l|}{ Level of education } \\
\hline No education & 6 & 1.5 \\
\hline Primary & 111 & 28.6 \\
\hline Secondary & 180 & 46.4 \\
\hline Tertiary & 90 & 23.5 \\
\hline \multicolumn{3}{|l|}{ Marital status } \\
\hline Single(never married) & 63 & 16.3 \\
\hline Married & 165 & 42.6 \\
\hline Widow & 81 & 20.9 \\
\hline Divorced/separated & 78 & 20.2 \\
\hline Currently having a partner & 238 & 61.4 \\
\hline \multicolumn{3}{|c|}{ HIV status of partner $(n=238)$} \\
\hline HIV Infected & 110 & 46.2 \\
\hline HIV uninfected & 67 & 28.2 \\
\hline Don't know & 61 & 25.6 \\
\hline \multicolumn{3}{|l|}{ Partners last 6 months } \\
\hline $\mathbf{0}$ & 140 & 36.3 \\
\hline 1 & 243 & 63 \\
\hline 2 & 2 & 0.5 \\
\hline 4 & 1 & 0.3 \\
\hline
\end{tabular}

Barriers to accessing cervical cancer screening services were determined by qualitative data. These included the following:

\section{Service provider as a barrier to accessing services}

There was a consensus among the participants that the gender and the age of the person conducting the cervical cancer screening services made them feel uncomfortable. This was seen as a huge barrier to accessing those services. Most participants reported that they would have wanted an older mature female nurse at the service point.

It matters whether it's a male or a female because if a female asks you to remove your underwear, you will not ask too many questions. But if you are alone with a man in the room who tells you to remove your underwear and you do not know the reason why, already you feel victimized as you are fearful because you know your HIV status and now this could be another problem. Some say Remove your underwear and lie there without much explanation. I did not ask what he wanted to do because there was a long line outside. Also I did not know he wanted to examine my genitals so it's only when he had completed that I understood what he was doing, "49 year old lady." I talked to some one on the queue. The women were fearful of a man seeing their private parts. I would prefer if a lady did it, "45 year old lady." The participants also felt that very little information concerning cancer of the cervix and screening is provided by the clinician as well as the person providing the service

"One should be educated completely on the procedure, and tell you if it's painful or not. Like for me the first day I went I was told to remove my underwear. I nearly ran away. So you see if I had been explained to earlier I would have been prepared. But if you have not been told you will get shocked especially if you come across a male nurse!" 52 year old lady.

\section{Fear of pain or excessive bleeding}

Some participants reported that they had heard that the procedure may cause excessive bleeding and severe pain. This caused them to fear and prevented them from accessing the services despite being referred by the clinician. They would therefore keep saying they are on their menses or that they will access the service in the next visit with no intention of doing so. Below are some themes alongside salient quotes from the participants:

"My husband died without me knowing his status. I used to have excessive bleeding and was sent for a pap smear which was done in clinic 66. I did not feel any pain even though I went to the clinic regularly for a pap smear over a period of 3 years. But the first time I was screened in CCC, I felt so much pain, I said I will not go again", 33 year old lady.

"I have never gone for screening even though I was asked to go by the doctor. I fear that it will be very painful", 50 year old lady. Sometimes you are not told what will be done. My friend "told me that it is very painful." When I did it I wanted to run away", 48 year old lady.

"I was also fearful, but when I realized my brother's wife died because of cancer of the cervix, I decided to do the screening early as it can be treated", 37 year old lady.

"Many people fear knowing the truth. Not only for cancer of the cervix, but also HIV and other diseases. It's just ignorance", 46 year old lady.

\section{Waiting time}

"I was sent by the doctor to be screened. I went and waited for two and a half hours and still no one came to attend to me", 38 year old lady.

"I know how important cervical cancer screening is because it saved my life. I was detected with cancer early and treatment done, but I don't want to keep waiting", 55 year old lady. "I took two hours before I could be seen", 40 year old lady. 
Table 2: Correlates of cervical cancer screening among women attending KNH CCC.

\begin{tabular}{|c|c|c|c|c|}
\hline \multirow{2}{*}{ Characteristics } & \multicolumn{2}{|c|}{ Cervical cancer screening } & \multirow{2}{*}{ OR $(95 \% \mathrm{CI})$} & \multirow{2}{*}{ P-Value } \\
\hline & Yes n (\%) & Non $(\%)$ & & \\
\hline \multicolumn{5}{|l|}{ Age in years } \\
\hline$<25$ & $2(22.2)$ & $7(77.8)$ & 1.0 & \\
\hline $25-35$ & $47(43.1)$ & $62(56.9)$ & $2.7(0.5-13.4)$ & 0.237 \\
\hline$>35$ & $129(48.1)$ & $139(51.9)$ & $3.2(0.7-15.9)$ & 0.146 \\
\hline \multicolumn{5}{|l|}{ Occupation } \\
\hline Employed & $150(48.2)$ & $161(51.8)$ & 1.0 & 0.136 \\
\hline Not employed & $29(38.7)$ & $46(61.3)$ & $0.7(0.4-1.1)$ & \\
\hline \multicolumn{5}{|l|}{ Level of education $n=387$} \\
\hline No education & $2(33.3)$ & $4(66.7)$ & $0.6(0.1-3.2)$ & 0.523 \\
\hline Primary & $52(46.8)$ & $59(53.2)$ & 1.0 & \\
\hline Secondary & $83(46.4)$ & 96 (53.6) & $1.0(0.6-1.6)$ & 0.937 \\
\hline Tertiary & $42(46.2)$ & $49(53.8)$ & $1.0(0.6-1.7)$ & 0.922 \\
\hline \multicolumn{5}{|l|}{ Marital Status $n=386$} \\
\hline Single(Never married) & $26(41.9)$ & $36(58.1)$ & 1.0 & \\
\hline Married & $80(48.5)$ & $85(51.5)$ & $1.3(0.7-2.4)$ & 0.379 \\
\hline Widow/Divorced/separated & $73(45.9)$ & $86(54.1)$ & $1.2(0.7-2.1)$ & 0.593 \\
\hline \multicolumn{5}{|c|}{ HIV status of partner $n=385$} \\
\hline HIV Infected & $52(47.3)$ & $58(52.7)$ & $1.2(0.7-1.9)$ & 0.529 \\
\hline HIV uninfected & $30(44.8)$ & $37(55.2)$ & $1.1(0.6-1.9)$ & 0.883 \\
\hline Currently no partner & $64(43.2)$ & $84(56.8)$ & 1.0 & \\
\hline Don't know & $31(51.7)$ & $29(48.3)$ & $1.4(0.8-2.6)$ & 0.286 \\
\hline \multicolumn{5}{|c|}{ Partners have last 6 month $n=387$} \\
\hline$<=1$ & $177(46.1)$ & $207(53.9)$ & $0.8(0.5-1.2)$ & 0.269 \\
\hline$>1$ & $2(66.7)$ & $1(33.3)$ & 1.0 & \\
\hline \multicolumn{5}{|l|}{ CCS recommended by staff } \\
\hline Yes & $178(54.4)$ & $149(45.6)$ & $10(4.2-23.9)$ & $<0.001$ \\
\hline No & $6(10.7)$ & $50(89.3)$ & 1.0 & \\
\hline \multicolumn{5}{|c|}{ Had CCS before joining KNH CCC } \\
\hline Yes & $55(67.9)$ & $26(32.1)$ & $2.9(1.7-4.9)$ & $<0.001$ \\
\hline No & $128(42.2)$ & $175(57.8)$ & 1.0 & \\
\hline \multicolumn{5}{|c|}{ Quality of information in CCS services $(n=383)$} \\
\hline Poor & $5(17.9)$ & $23(82.1)$ & 1.0 & 0.408 \\
\hline Average & $20(25.6)$ & $58(74.4)$ & $1.6(0.5-4.7)$ & \\
\hline Good & $127(53.8)$ & $109(46.2)$ & $5.4(2.0-14.6)$ & 0.001 \\
\hline Very good & $27(65.9)$ & $14(34.1)$ & $8.9(2.8-28.4)$ & $<0.001$ \\
\hline
\end{tabular}

\section{DISCUSSION}

Previous cervical cancer screening before joining the clinic was low at $21 \%$ compared to $46 \%$ after joining the clinic, contrasting with findings obtained in a study in Nigeria which aimed to determine acceptability of cervical cancer screening. ${ }^{16}$ That study found previous cervical cancer screening very low at $9.7 \%$ but a significant increase to $79.8 \%$ after joining the clinic.

A cervical cancer screening acceptance rate of $44 \%$ was obtained in a study to determine the acceptance of free cervical cancer screening in Coptic Hospital, Kenya. ${ }^{17}$ This rate was similar to that found in this study. In yet another Kenyan study, the uptake of cervical cancer screening services under the FACES program showed impressive uptake of $87 \% .{ }^{10}$ This however came after rigorous community awareness coupled with care giver capacity building. The study found that staff recommendation for screening and previous screening before enrolment into the CCC significantly increased uptake of the service.

This highlights the important role that staff plays in the acceptance of service utilization. However, while $85.2 \%$ of all participants responded that cervical cancer screening had been recommended to them, only $46 \%$ had been screened. This shows a poor uptake of the screening service despite recommendation by a health care giver. 
Some reasons for this poor uptake were identified during qualitative data collection as falling under the themes: fear of an intrusive procedure; waiting time; and service provider barrier where the patient unexpectedly found a male nurse or where poor or no information of the procedure was provided. These findings are shared with other studies in sub-Saharan African countries. ${ }^{12-14}$ Factors associated with acceptance of cervical cancer screening include age and years of HIV diagnosis. Increasing age reduced the likelihood of accepting screening. Reasons for this may be the difference in age and gender between the client and the service provider- a finding obtained by qualitative data following focus group discussions. These findings are similar to those in a Zimbabwe study where women aged more than 45 years were significantly less likely to have cervical cancer screening. ${ }^{18}$

In yet another study, $\mathrm{Yi}$ et al reported that socioeconomic status, marital status and level of education significantly contributed towards cervical cancer screening among Cambodian women in USA. In the KNH CCC study, marital status, occupation, number of partners or education level did not have any influence on whether or not a patient accepted cervical cancer screening, probably because referral was primarily provider initiated. ${ }^{15}$

On customer satisfaction, those who had had screening were significantly more likely to rate the services as being good or very good. This implies that possible negative misconceptions among those not screened may influence the decision to be screened, explaining further why less than $50 \%$ of all patients to whom screening had been recommended were actually screened.

\section{CONCLUSION}

Cervical cancer screening uptake was low despite health care givers recommending the service. Staff recommendation and previous screening significantly influenced uptake of the service. Barriers in accessing the services included lack of proper communication of procedures, fear of pain and increased waiting time.

\section{ACKNOWLEDGEMENTS}

Authors would like to acknowledge the Kenyatta National Hospital, Department of Research and Programs for funding and facilitating the success of this research. They would also like to acknowledge the HIV care and treatment clinic in Kenyatta National Hospital management, staff and the patients enrolled in this study for their support and cooperation during the study period.

Funding: No funding sources Conflict of interest: None declared

Ethical approval: The study was approved by the Institutional Ethics Committee

\section{REFERENCES}

1. Parkin P, Pisani J, Ferlay DM. Global cancer statistics. Cancer J Clin. 1999;49(1):33-64.

2. Wright TC, Ellerbrock TV, Chiasson MA. Cervical intraepithelial neoplasia in women infected with human immunodeficiency virus: prevalence, risk factors, and validity of papanicolaou smears. Obstet Gynecol. 1994;8:99-106.

3. Ellerbrock TV, Chiasson MA, Bush TJ. Incidence of cervical squamous intraepithelial lesions in HIVinfected women. JAMA. 2000;283:1031.

4. Moscicki AB, Ellenberg JH, Nowick P. Risk of highgrade squamous intraepithelial lesion in HIVinfected adolescents. J Infect Dis. 2004;190:1413.

5. Austrickler HD, Burk RD, Fazzari M, Anastos K. Natural history and possible reactivation of human papillomavirus in human immunodeficiency viruspositive women. J Natl Cancer Inst. 2005;97(8):577.

6. Clifford GM, Gonçalves MA, Franceschi S. Human papillomavirus types among women infected with HIV: a meta-analysis. HPV and HIV study group. AIDS. 2006;20(18):2337.

7. Frisch M, Biggar RJ, Goedert JJ. Human papillomavirus-associated cancers in patients with human immunodeficiency virus infection and acquired immunodeficiency syndrome. J Natl Cancer Inst. 2000;92(18): 1500.

8. NASCOP. Guidelines for Antiretroviral treatment in Kenya. 2011.

9. International AIDS vaccine initiative HPV vaccine adoption in developing countries: cost and financing. Available at http://www.iavi.org/, http:// www.path. org/publications/. Accessed on 8 April 2012.

10. Megan J, Huchko, Elizabeth A, Bukusi, Craig R. Cohen successful integration of a cervical cancer screening and prevention. Int $\mathbf{J}$ Gynecol Obst. 2011;114(2):106-10.

11. Sandelowski M. Sample size in qualitative research. Research Nursing Health. 1995;5:89-95.

12. Machoki JM, Rogo KO. Knowledge and attitudinal study of Kenyan women in relation to cervical carcinoma. Int J Gynecol Obst. 1991;34:55-9.

13. Ajayi IO, Adewole IF. Knowledge and attitude of general outpatient attendants in Nigeria to cervical cancer. Cent Afr J Med. 1998;44:41-3.

14. Adanu RM. Cervical cancer knowledge and screening in Accra, Ghana. J Womens Health Gend Based Med. 2002;11:487-8.

15. Arevian M, Noureddine S, Kabakian T. A survey of knowledge, attitude, and practice of cervical screening among Lebanese/Armenian women. Nurs Outlook. 1997;45:16-22.

16. Ezechi OC, Chidinma V, Okafor G. Ostergren and karen odberg pettersson willingness and acceptability of cervical cancer screening among HIV positive Nigerian women. BMC Public Health. 2013;13:46.

17. McKenzie K, Rogers R, Pamnani R, Warui D, Sakr $\mathrm{S}$, Ngumo R, et al. Free cervical cancer screening among HIV-positive women receiving antiretroviral 
treatment in Kenya: acceptance and findings. IAS. 2014;11:54-68.

18. Grangé G. Factors associated with regular cervical cancer screening. Int J Gynecol Obstet. 2008;11:4855 .
Cite this article as: Njuguna E, Ilovi S, Muiruri $\mathrm{P}$, Mutai K, Kinuthia J, Njoroge P. Factors influencing cervical cancer screening in a Kenyan Health

Facility: a mixed qualitative and quantitative study. Int J Reprod Contracept Obstet Gynecol 2017;6:1180-5. 